\title{
The combination astemizole-gefitinib as a potential therapy for human lung cancer
}

This article was published in the following Dove Press journal:

OncoTargets and Therapy

\author{
María de Guadalupe \\ Chávez-López' \\ Violeta Zúñiga-García' \\ Elisabeth Hernández- \\ Gallegos' \\ Eunice Vera' \\ Carmen Alexandra \\ Chasiquiza-Anchatuña ${ }^{1,2}$ \\ Marco Viteri-Yánez ${ }^{1,2}$ \\ Janet Sanchez-Ramos ${ }^{3}$ \\ Efraín Garrido ${ }^{3}$ \\ Javier Camacho' \\ 'Department of Pharmacology, Center \\ for Research and Advanced Studies \\ of the National Polytechnic Institute, \\ Mexico City, Mexico; ${ }^{2}$ Department \\ of Life Sciences and Agriculture, \\ University of the Armed Forces ESPE, \\ Sangolquí, Ecuador; ${ }^{3}$ Department \\ of Genetics and Molecular Biology, \\ Center for Research and Advanced \\ Studies of the National Polytechnic \\ Institute, Mexico City, Mexico
}

\begin{abstract}
Lung cancer is a major cause of cancer mortality. Thus, novel therapies are urgently needed. Repositioning of old drugs is gaining great interest in cancer treatment. Astemizole is an antihistamine proposed to be repositioned for cancer therapy. This drug targets several molecules involved in cancer including histamine receptors, $\mathrm{ABC}$ transporters and the potassium channels Eag 1 and HERG. Astemizole inhibits the proliferation of different cancer cells including those from cervix, breast, leukemia and liver. Gefitinib is widely used to treat lung cancer; however, no response or drug resistance occurs in many cases. Here, we studied the combined effect of astemizole and gefitinib on the proliferation, survival, apoptosis and gene and protein expression of Eag1 channels in the human lung cancer cell lines A549 and NCI-H1975. Cell proliferation and survival were studied by the MTT method and the colony formation assay, respectively; apoptosis was investigated by flow cytometry. Gene expression was assessed by real-time polymerase chain reaction (RT-PCR), and protein expression was studied by Western blot analysis and immunocytochemistry. We obtained the inhibitory concentrations 20 and $50\left(\mathrm{IC}_{20}\right.$ and $\mathrm{IC}_{50}$, respectively) values for each drug from the cell proliferation experiments. Drug combination at their $\mathrm{IC}_{20}$ had a superior effect by reducing cell proliferation and survival in up to $80 \%$ and $100 \%$, respectively. The drugs alone did not affect apoptosis of $\mathrm{H} 1975$ cells, but the drug combination at their $\mathrm{IC}_{20}$ increased apoptosis roughly four times in comparison to the effect of the drugs alone. Eag1 mRNA levels and protein expression were decreased by the drug combination in A549 cells, and astemizole induced subcellular localization changes of the channel protein in these cells. Our in vitro studies strongly suggest that the combination astemizole-gefitinib may be a novel and promising therapy for lung cancer patients.
\end{abstract}

Keywords: astemizole, gefitinib, potassium channels, lung cancer

\section{Introduction}

Lung cancer is the major cause of cancer-related deaths worldwide. ${ }^{1,2}$ Most of the primary lung cancers are non-small-cell lung cancer (NSCLC). ${ }^{3,4}$ The most important oncogene drivers in NSCLC patients are mutations in the epidermal growth factor receptor (EGFR) gene; actually, activating mutations are a prime therapeutic target. . $^{5,6}$ The most common "sensitizing mutations" in EGFR (exon 19 deletions and exon 21 L858R mis-sense substitutions) result in constitutive activation of the receptor without ligand binding. In accordance, some of the EGFR tyrosine kinase inhibitors (TKIs) target mutant EGFRs. ${ }^{5,7-9}$ The first-generation EGFR inhibitors such as gefitinib were the first EGFR-targeted therapies to be registered and later approved by the US Food and Drug Administration (FDA) as a treatment for lung cancer. ${ }^{6,10}$ Unfortunately, although many patients initially respond to EGFR-targeted therapies, most of them eventually developed resistance and relapsed. ${ }^{11}$ One of the mechanisms of drug resistance involves the extrusion of TKIs by ATP-binding cassette (ABC) multidrug efflux pumps. ${ }^{12,13}$ ABCG2 (breast cancer resistance protein) transports gefitinib which also interacts with
Correspondence: Javier Camacho Department of Pharmacology, Center for Research and Advanced Studies of the National Polytechnic Institute, Avenida Instituto Politécnico Nacional 2508, Mexico City 07360, Mexico

Tel +525557473800 ext 5416

Fax +52 5557477002

Email fcamacho@cinvestav.mx
OncoTargets and Therapy 2017:10 5795-5803

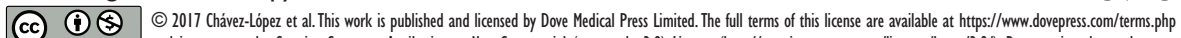
cc) hereby accept the Terms. Non-commercial uses of the work are permitted without any further permission from Dove Medical Press Limited, provided the work is properly attributed. For permision for commercial use of this work, please see paragraphs 4.2 and 5 of our Terms (htpps://www.dovepress. com/terms.php). 
$\mathrm{ABCB} 1$ and $\mathrm{ABCC} 1{ }^{14}$ Because drug resistance decreases the efficacy of the drug, it is necessary to find alternative therapeutic strategies for lung cancer patients.

Drug repositioning involves the identification of novel indications for already existing, well-characterized and welltolerated drugs reducing costs and bypassing safety concerns; this reposition strategy has emerged as an attractive alternative for cancer treatment. ${ }^{15-18}$ Astemizole is an anti-histamine that has gained enormous interest to be repositioned for cancer treatment because it targets several molecules involved in cancer including $\mathrm{H} 1$ histamine receptors, P-glycoproteins and members of the potassium channel family ether à-go-go. ${ }^{19-28}$ Human ether à go-go-1 (Eag1, Kcnh1 and Kv10.1) is a voltage-gated channel that displays oncogenic properties and has gained great interest in cancer research. ${ }^{25,26,29,30}$ The distribution of Eag1 is very restricted in normal tissues. It is mainly expressed in the brain, but low amounts can be detected in placenta, testes and adrenal glands and transiently in myoblasts. ${ }^{29,31,32}$ Conversely, Eag1 is overexpressed in most human tumors, including liver, cervical, lung, breast, colon and prostate cancer. ${ }^{28,32-35}$ Astemizole decreases tumor cell proliferation in vitro in breast, liver, cervical and lung cancer cell lines as well as in in vivo breast and liver cancer models. ${ }^{16,24,28,36}$ In addition, astemizole potentiates the effect of other anticancer drugs in leukemia and breast cancer cells and downregulates Eag1 mRNA expression in breast cancer cells; in addition, astemizole binds to chromatine. ${ }^{36-39}$ Interestingly, the use of astemizole and loratadine was associated with reduced mortality from different cancers, and astemizole induced sensitization to chemotherapy and reversion of multidrug resistance in NSCLC cells. ${ }^{16}$

Therefore, because of the high mortality-to-incidence ratio of lung cancer and the potential use of anti-histamines in cancer treatment as well as due to the multitarget properties of astemizole and its synergism with anticancer drugs, here we investigated whether the combination astemizole-gefitinib may be a potential anticancer treatment for lung cancer cells.

\section{Materials and methods}

\section{Cells lines and reagents}

The human NSCLC cell lines A549 and NCI-H1975 were obtained from the American Type Culture Collection (Manassas, VA, USA) and cultured according to the manufacturer's instructions. Astemizole and DMSO were purchased from Sigma-Aldrich Co. (St Louis, MO, USA). Gefitinib (Iressa ${ }^{\circledR}$, ZD1839) was kindly provided by AstraZeneca plc (Cambridge, UK). The anti-Eag1 antibody was purchased from Novus International (Littleton, CO, USA) and the anti-actin antibody from Sigma-Aldrich Co.

\section{Metabolic activity}

Cell proliferation (assessed by metabolic activity) was assayed by a colorimetric method with 3-(4,5-dimethylthiazol-2-yl)2,5-diphenyltetrazolium bromide (MTT) as described previously. ${ }^{28}$ Briefly, $3 \times 10^{3}$ cells per well were seeded in 96-well plates and incubated for 72 hours in culture medium either alone or in the presence of astemizole, gefitinib or DMSO as vehicle. MTT $(0.5 \mathrm{mg} / \mathrm{mL})$ was added 4 hours before completing the whole incubation time. Absorbance data were obtained with a microplate photometer (Sunrise Touchscreen).

\section{Colony formation assay}

Cell survival was studied with the colony formation assay. Briefly, $2 \times 10^{2}$ A549 and $5 \times 10^{2}$ NCI-H1975 cells were cultured in $60 \mathrm{~mm}$ Petri dishes to allow the growth of colonies from single separated cells. Twenty-four hours after plating, the cells were incubated for 72 hours in culture medium alone or in the presence of DMSO or the drugs. Afterward, A549 and NCI-H1975 cells were left to grow for 6 and 11 days more, respectively, in the absence of the drugs. Then, cells were fixed in ethanol (absolute grade) for 15 minutes, stained with crystal violet (1\%) for 15 minutes and then rinsed four times with water, observed with a microscope and counted.

\section{Apoptosis}

Apoptosis was studied by flow cytometry as described previously. ${ }^{28}$ Briefly, $4 \times 10^{4}$ cells were seeded in culture plates and incubated during 72 hours in culture medium alone or in the presence of astemizole, gefitinib or vehicle (DMSO). Camptothecin (apoptosis inductor) and methanol (necrosis inductor) were used as controls. Apoptosis was determined with the Annexin V-FITC kit (Thermo Fisher Scientific, Waltham, MA, USA) binding to phosphatidylserine and DNA staining by propidium iodide (PI). Experiments were performed by flow cytometry (CYAN ADP; Dako, Glostrup, Denmark). Percentages of viable (FITC-negative and PI-negative), apoptotic (FITC-positive and PI-negative) and late apoptotic (FITC-positive and PI-positive) cells were obtained by quadrant analysis using the Summit 4.3 software.

\section{Immunocytochemistry}

Cell lines were grown on charged glass slides and boiled for antigen retrieval, then blocked with endogenous peroxidase blocker (Bio SB, Santa Barbara, CA, USA) for 10 minutes and then incubated in the presence of 1:500 anti-Eag1 antibody overnight at $4^{\circ} \mathrm{C}$. The slides were then incubated with secondary biotin antibody (Bio $\mathrm{SB}$ ) for 15 minutes and then incubated with streptavidin polymer (Bio SB) for 15 minutes. 
The specific staining reaction was completed by incubating the slides in the presence of diaminobenzidine in buffer reaction solution (Bio $\mathrm{SB}$ ) and observed as a brown staining. Sections were counterstained with hematoxylin (Dako). The slides were observed in an Olympus IX51 microscope, Olympus DP70 camera (Tokyo, Japan).

\section{Real-time polymerase chain reaction (RT-PCR)}

Total RNA was extracted from cell cultures with TRIzol reagent. Five micrograms of total RNA was reverse transcribed using the Moloney Murine Leukemia Virus Reverse transcriptase (M-MuLV) (New England BioLabs Inc., Ipswich, MA, USA). RT-PCR was performed with $1 \mu \mathrm{L}$ of cDNA using the TaqMan ${ }^{\mathrm{TM}}$ detection system (Thermo Fisher Scientific) and the Universal PCR Master Mix reagents kit (Thermo Fisher Scientific). Probes previously developed from TaqMan were used to study Eag1 (ID: Hs00924320_m1) and Gusb (ID: Hs00939627_m1, as a constitutive gene) expression. The PCR reaction protocol was $95^{\circ} \mathrm{C}$ for 15 seconds and $60^{\circ} \mathrm{C}$ for 1 minute ( 40 cycles). Data were analyzed with the $2^{-\Delta \Delta \mathrm{Ct}}$ method.

\section{Western blot}

Cells were washed, scrapped and centrifuged, and the obtained pellet was resuspended in lysis buffer supplemented with protease inhibitors. Lysis was completed with the freezing-thawing process; the lysate was centrifuged and the supernatant collected. Forty micrograms of protein was separated on sodium dodecyl sulfate polyacrylamide gel electrophoresis (10\%), transferred to a nitrocellulose membrane and incubated with either the anti-Eag1 antibody (1:750) or the anti-actin antibody $(1: 100,000)$. The relative protein quantification was performed with the ImageJ software (NIH, Bethesda, MD, USA).

\section{Statistical analysis}

Statistical analysis was performed with analysis of variance (ANOVA) followed by the Tukey-Kramer test using GraphPad Prism software version 5.0 (La Jolla, CA, USA). The differences between the drug combination groups and either the drug-alone groups at the corresponding concentration or the control or the vehicle are shown. The analysis of Western blot data was performed with the Student's $t$-test. $P$-values $<0.05$ were considered to be statistically significant.

\section{Results}

\section{Concentration-dependent effect} of astemizole and gefitinib on the proliferation of lung cancer cells

We first investigated the effect of astemizole and gefitinib alone on the proliferation of A549 and NCI-H1975 lung cancer cells, assessed by the metabolic activity. The effect of gefitinib is well known in both cell lines, ${ }^{40,41}$ and the effect of astemizole has been previously reported in A549 cells. ${ }^{16}$ As expected, both drugs decreased the metabolic activity in a concentration-dependent manner in both cell lines (Figure 1).
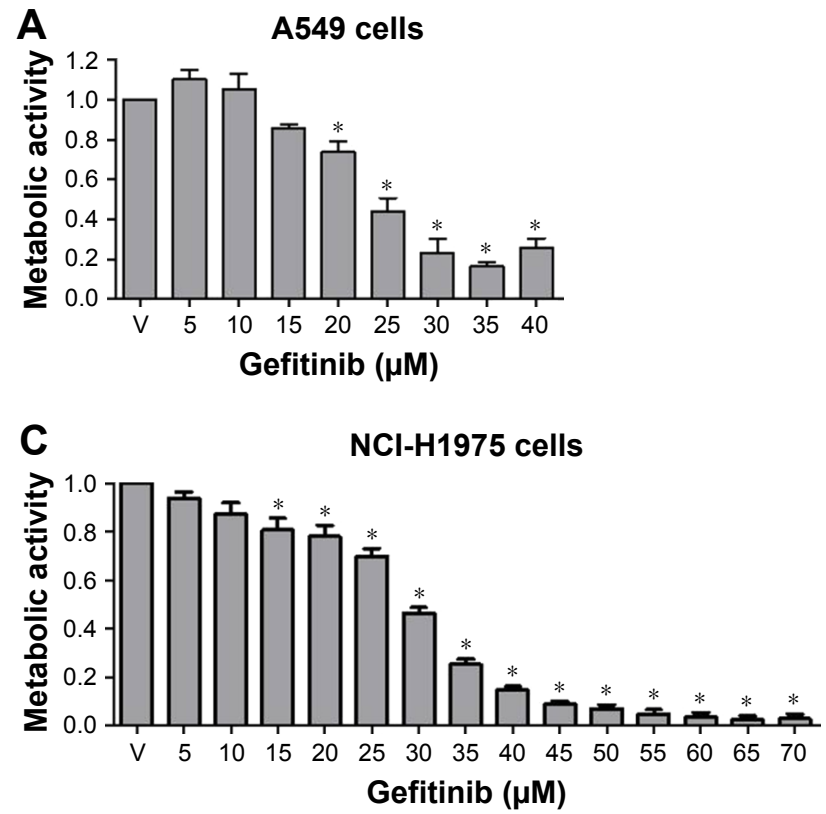
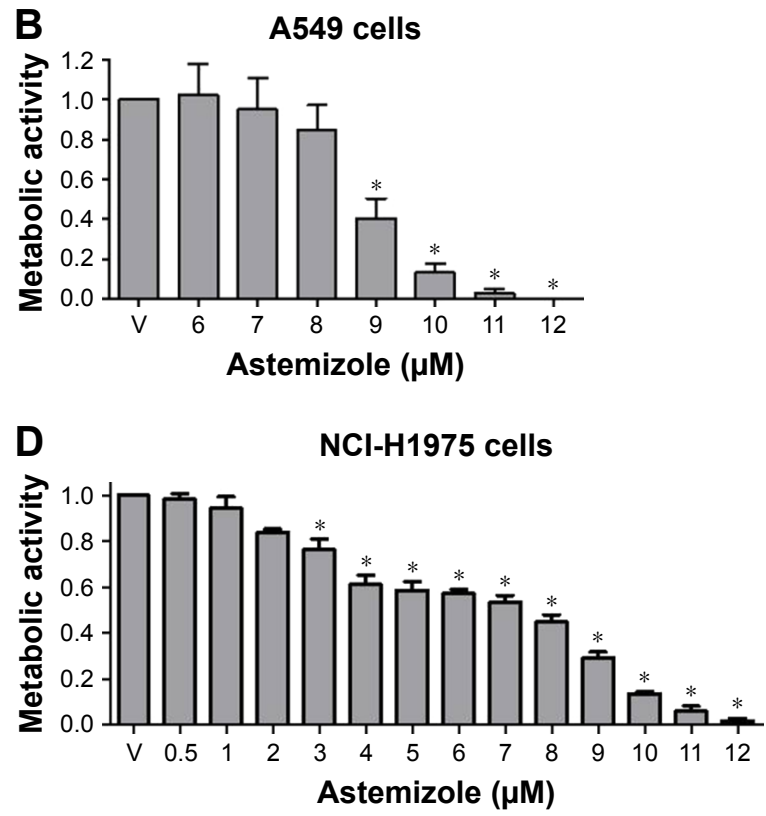

Figure I Effect of astemizole or gefitinib on the metabolic activity of lung cancer cells.

Notes: Astemizole or gefitinib decreased the proliferation of A549 (A and B) and NCl-HI975 (C and D) lung cancer cells in a concentration-dependent manner. Four different cell cultures were performed with six technical replicates each. Mean \pm SD, $* p<0.05$ vs vehicle (V [DMSO]). 
Table I Inhibitory concentrations (ICs) of astemizole or gefitinib in the proliferation of human lung cancer cells

\begin{tabular}{|c|c|c|c|c|}
\hline \multirow[t]{2}{*}{ Cell line } & \multicolumn{2}{|c|}{$\begin{array}{l}\text { Astemizole } \\
(\mu \mathrm{M})\end{array}$} & \multicolumn{2}{|c|}{$\begin{array}{l}\text { Gefitinib } \\
(\mu \mathrm{M})\end{array}$} \\
\hline & $I_{20}$ & $I C_{50}$ & $\mathrm{IC}_{20}$ & $I_{50}$ \\
\hline A549 & 7.5 & 9.2 & 15 & 26.48 \\
\hline NCl-HI975 & 7.75 & 8.85 & 21.56 & 29.62 \\
\hline
\end{tabular}

From these experiments, we obtained the $\mathrm{IC}_{20}$ and $\mathrm{IC}_{50}$ values for each drug in each cell line (Table 1).

\section{Enhanced effect of the combination} astemizole-gefitinib on the proliferation, survival and apoptosis of lung cancer cells Cell proliferation experiments combining the drugs at their $\mathrm{IC}_{20}$ and $\mathrm{IC}_{50}$ concentrations were performed. The combination of the drugs had superior anti-proliferative effects in both cell lines. Astemizole- $\mathrm{IC}_{20}$ in combination with gefitinib$\mathrm{IC}_{20}$ decreased metabolic activity by $80 \%$, whereas the combination of astemizole- $\mathrm{IC}_{20}$ and gefitinib- $\mathrm{IC}_{50}$ decreased metabolic activity by $95 \%$ in A549 cells (Figure 2A). In the NCI-H1975 cells, the combinations of astemizol- $\mathrm{IC}_{20}$ plus gefitinib- $\mathrm{IC}_{20}$ and astemizole- $\mathrm{IC}_{20}$ plus gefitinib- $\mathrm{IC}_{50}$ showed a decrease of metabolic activity by $65 \%$ and $90 \%$, respectively (Figure $2 \mathrm{~A}$ ). Based on these results, for the rest of the experiments, we decided to focus on the drug combination at the $\mathrm{IC}_{20}$ found in the cell proliferation assays (Table 1).

Cell survival (assessed by the colony formation assay) was decreased in a very pronounced manner by the drug combination in comparison with the drugs alone in both cell lines (Figure 2B). In this assay, the combination
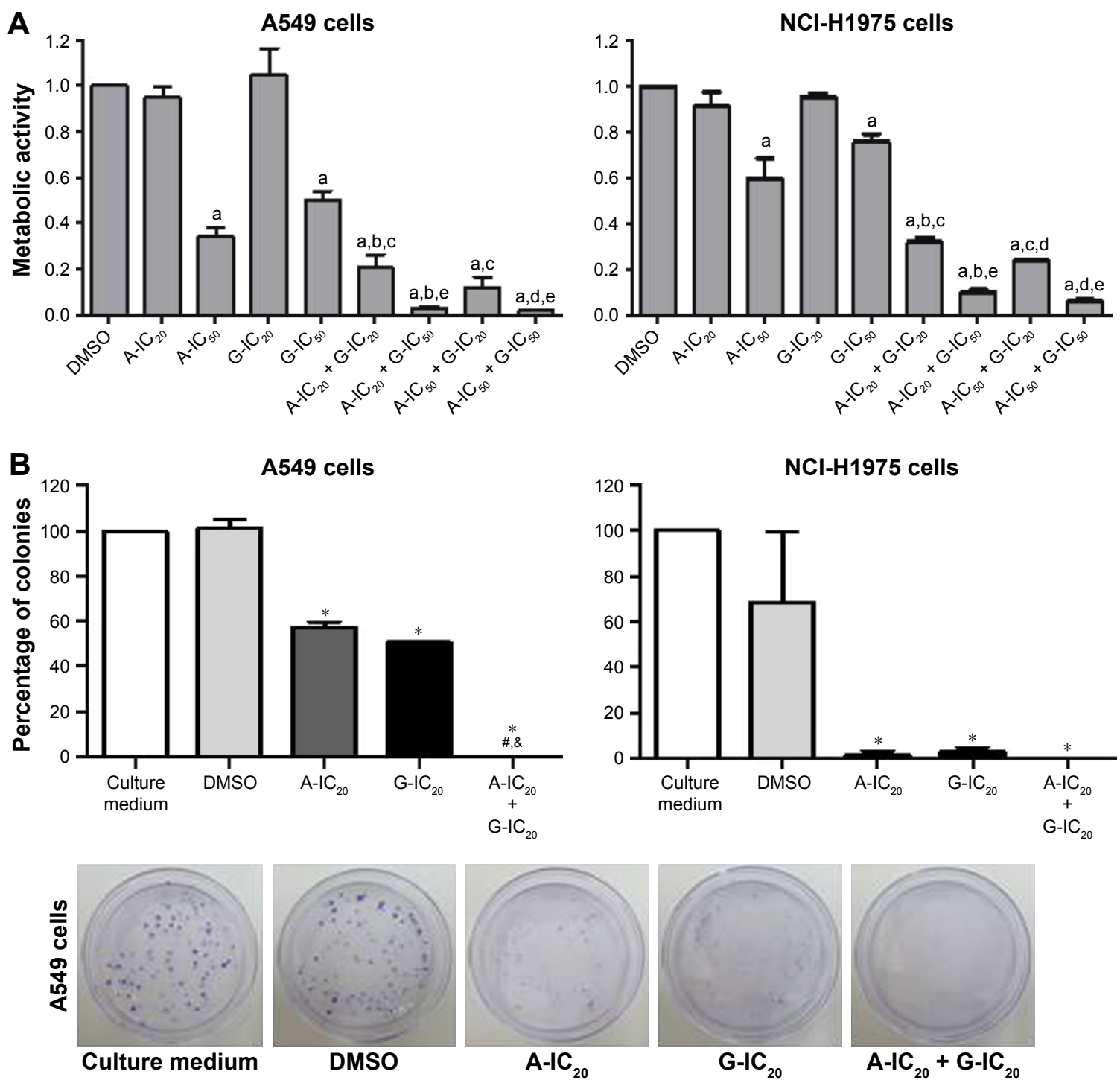

Figure 2 (Continued) 
C
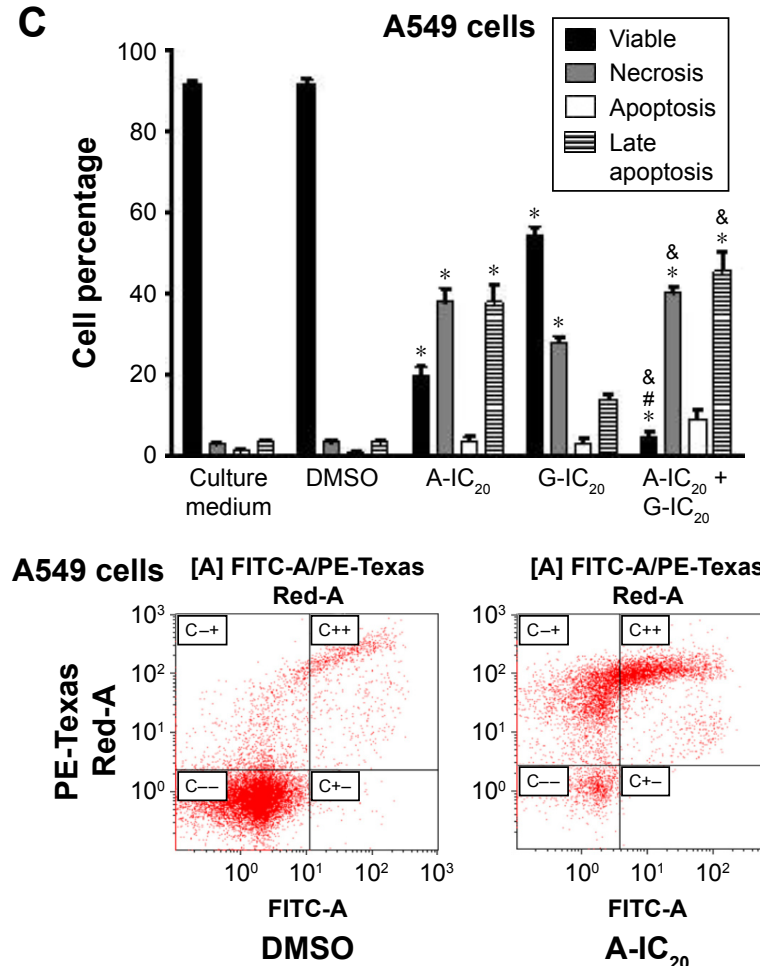

[A] FITC-A/PE-Texas

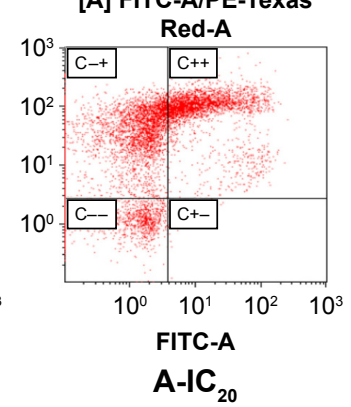

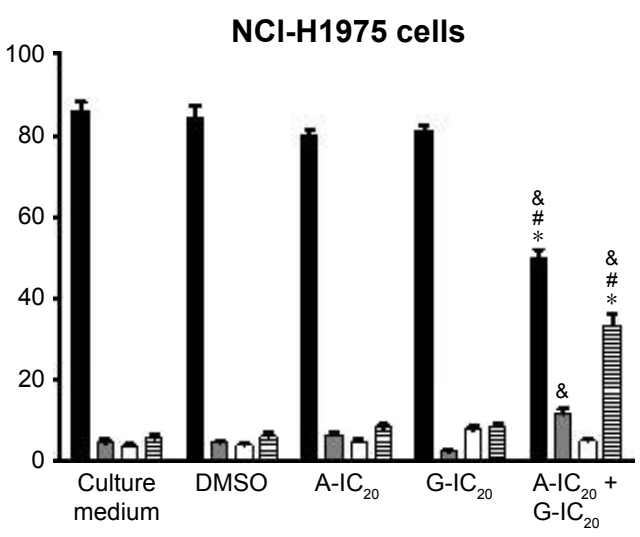

[A] FITC-A/PE-Texas
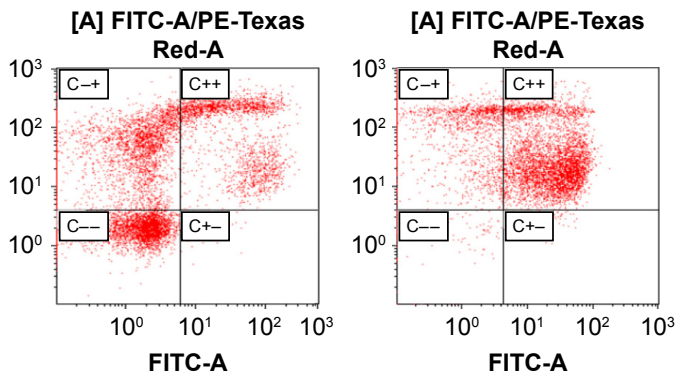

$A-I C_{20}+G-I C_{20}$

Figure 2 Enhanced effect of the combination astemizole-gefitinib on the metabolic activity, survival and apoptosis of lung cancer cells

Notes: The combinations of the drugs at different ICs had outstanding effects on metabolic activity $(\mathbf{A})$ in comparison with the effects of the drugs alone at their corresponding concentrations. Some of the most superior effects were observed when combining astemizole and gefitinib at their IC $C_{20}\left(A-I C_{20}\right.$ and $G-I C_{20}$, respectively), and $A-I C_{20}$, with $G-I C_{50}$ in both cell lines. Four different cell cultures were performed with eight technical replicates each. Mean \pm SD, ${ }^{a} p<0.05$ vs vehicle (DMSO), ${ }^{b} p<0.05$ vs $A-I C_{20}$, $p<0.05$ vs $G-I C_{20}$, ${ }^{\mathrm{d}} p<0.05$ vs $\mathrm{A}-\mathrm{IC} \mathrm{C}_{50}$ and ${ }^{\mathrm{e}} \mathrm{p}<0.05$ vs G-IC${ }_{50}$. Colony formation assays $(\mathbf{B})$ showed that both drugs decreased cell survival, but the effect was significantly stronger with the drug combination in both cell lines. Representative images of A549 colonies are shown in the bottom of the panel. Three different cell cultures were performed with three technical replicates each. Mean \pm SD, ${ }^{*} p<0.05$ vs medium and vehicle (DMSO), ${ }^{*} p<0.05$ vs A-IC 20 and ${ }^{*} p<0.05$ vs G-IC ${ }_{20}$. Astemizole, gefitinib and the drug combination significantly increased apoptosis in comparison with controls in A549 cells (C), but the effect of the combination was not higher than that produced by astemizole alone. However, in $\mathrm{NCl}-\mathrm{HI} 975$ cells, the drugs alone did not increase apoptosis in comparison with controls, but the drug combination was the only condition that clearly increased apoptosis in comparison with the rest of the groups. Representative plots from FACS experiments in A549 cells indicating the different quadrants separating the cell populations (bottom panels). Four different cell cultures were tested with three technical replicates each. Mean $\pm S D,{ }^{*} p<0.05$ vs vehicle (DMSO), ${ }^{\#} p<0.05$ vs $A-I C_{20},{ }^{\circledR} p<0.05$ vs $G-I C_{20}$.

Abbreviations: A, astemizole; G, gefitinib; FACS, fluorescence-activated cell sorting.

decreased cell survival completely in both cell lines. Some representative images are shown in Figure 2B. Then, we studied apoptosis by flow cytometry. The drug combination decreased the percentage of viable cells more than the drugs alone in A549 cells, but the effect of the combination on apoptosis was not higher than that produced by astemizole alone (Figure 2C). However, while the drugs alone did not increase apoptosis in comparison with control experiments (in the absence of the drugs) in NCI-H1975 cells, the drug combination increased apoptosis almost four times in comparison with the effect of any of the drugs alone (Figure 2C).

\section{The combination astemizole-gefitinib regulates Eagl channel expression}

Because Eag1 channel is one of the potential targets of astemizole, and channel expression is regulated by this drug in breast cancer cells,${ }^{36}$ we wondered if the drug treatment might regulate Eag1 expression in both cell lines.
The drug treatment did not modify Eag 1 mRNA levels or protein expression in NCI-H1975 cells (data not shown). However, while the drugs alone did not affect Eag1 mRNA expression in A549 cells, the drug combination decreased Eag1 mRNA levels by $75 \%$ in comparison with the expression in either control experiments or the presence of any drug alone (Figure 3A). Western blot analysis also revealed that the drug treatment significantly decreased Eag1 protein expression in A549 cells (Figure 3B and C). Immunocytochemistry studies showed that control cells treated with either the vehicle or astemizole displayed strong brown immunostaining (Figure 3D-E). Despite that immunostaining was not that strong in the gefitinib-treated cells (Figure 3F), the weakest signal was observed in the cells treated with the drug combination (Figure 3G). Interestingly, astemizole induced subcellular accumulation of the channel in some parts of the cell adjacent to the nucleus (Figure 3E). This subcellular rearrangement of Eag1 after treatment was exhibited only in A549 cells. 


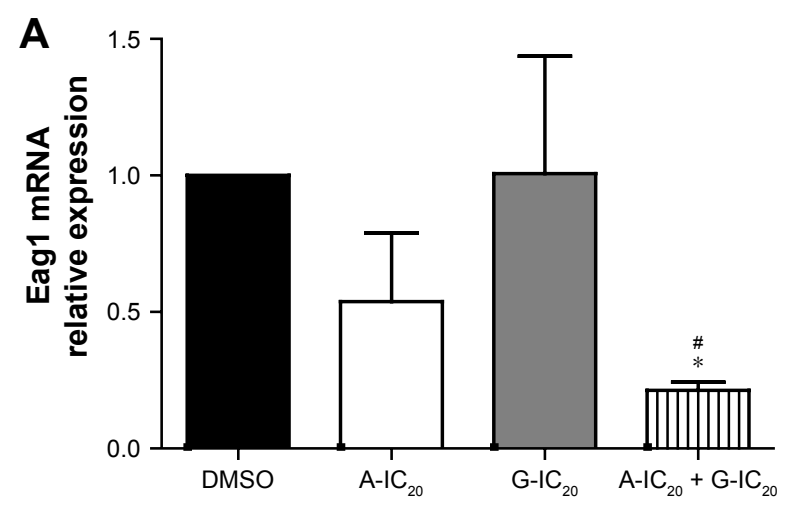

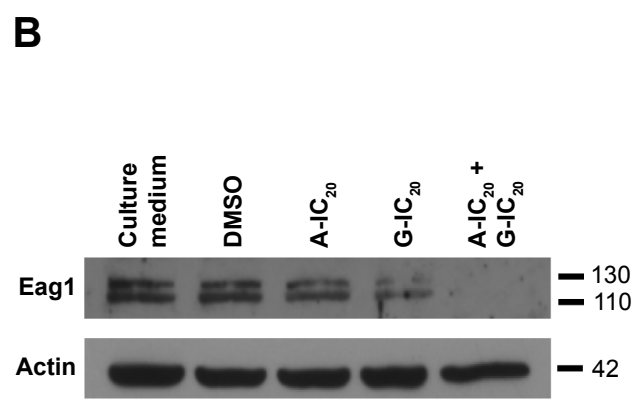

D

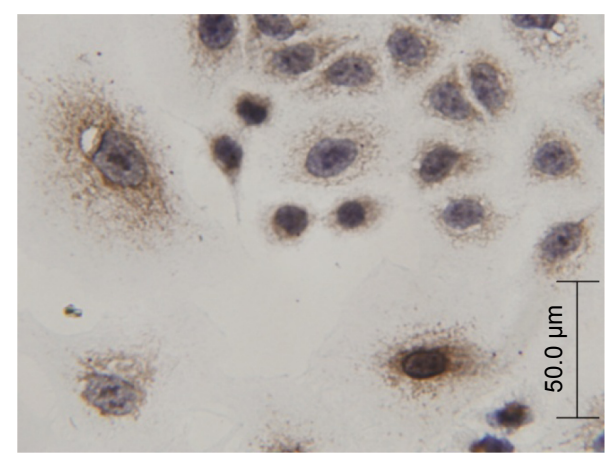

$\mathbf{F}$

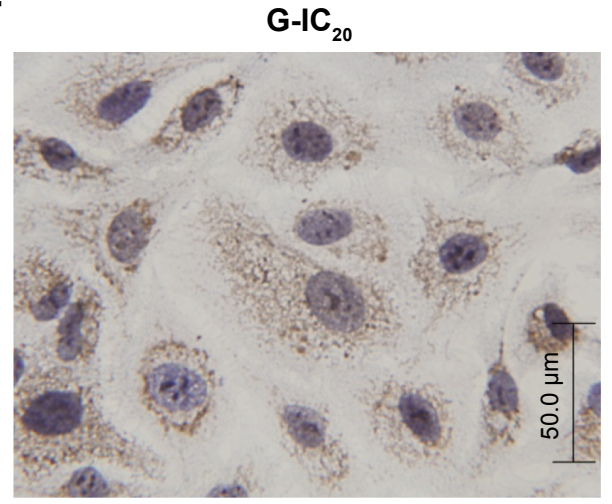

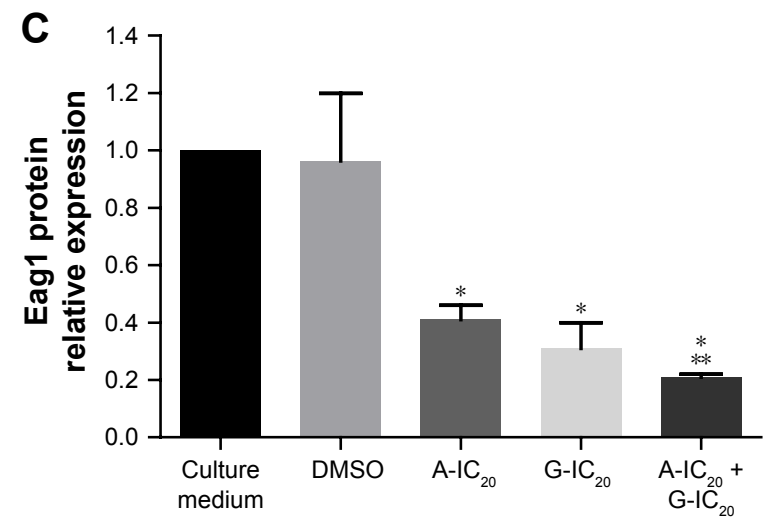

E
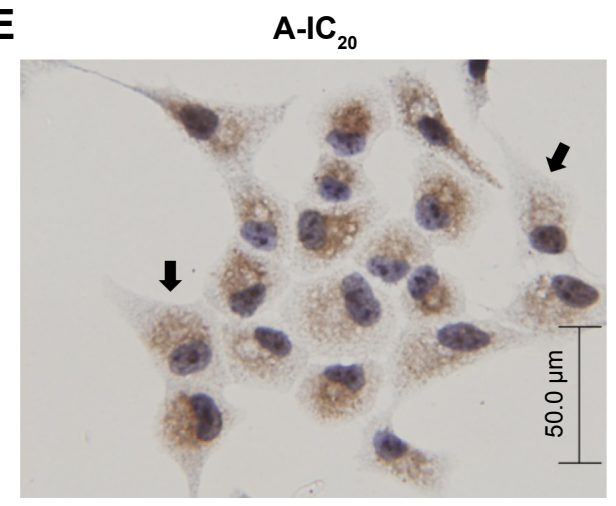

G

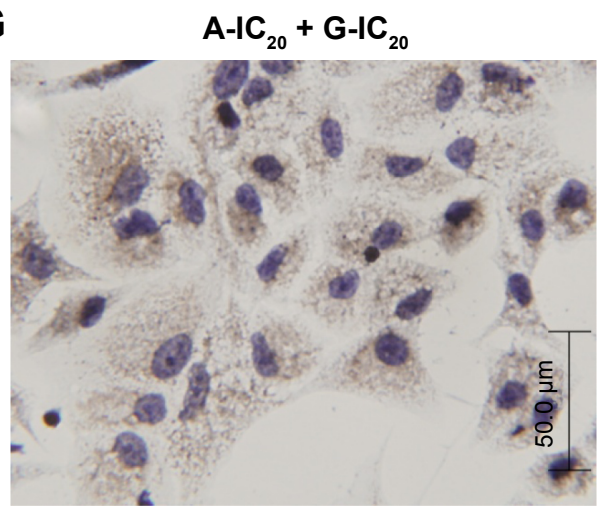

Figure 3 The combination astemizole-gefitinib downregulates Eagl expression in A549 cells.

Notes: (A) Relative EagI mRNA expression was decreased only in the cells treated with the drug combination. Mean \pm SD, ${ }^{*} p<0.05$ vs vehicle (DMSO), ${ }^{*}<<0.05$ vs $G-I C_{20}$. Western blot analysis revealed that Eagl protein expression is clearly downregulated by the drug treatment in a significant manner (B and $\mathbf{C})$. Mean \pm SD, ${ }^{*} p<0.05$ vs medium and vehicle (DMSO), $* * p<0.05$ vs $A-I C_{20}$. The presence of Eag I protein is revealed by immunocytochemistry as brown immunostaining (D-G). Vehicle-treated and astemizole-treated cells show strong Eagl expression in the cytoplasm ( $\mathbf{D}$ and $\mathbf{E}$, respectively), but astemizole induced subcellular localization changes in some areas adjacent to the nucleus. Gefitinib-treated cells $(\mathbf{F})$ showed less immunostaining, but the weakest signal was observed in the cells treated with the drug combination (G). Three different cell cultures were performed for all the experiments. Original magnification $=200 \times$.

Abbreviations: A, astemizole; G, gefitinib. 


\section{Discussion}

Lung cancer is the main cause of cancer-related deaths worldwide, and thus, identifying new therapeutic strategies is urgently needed. ${ }^{1,2}$ Unfortunately, most of the patients either do not respond or develop resistance to one of the most common treatments for lung cancer, namely, gefitinib. ${ }^{11}$ Recently, the anti-histamine astemizole has gained great interest by its anticancer effects, either alone ${ }^{20,22,23,25,28,42}$ or in combination. ${ }^{16,20,36,37}$ In addition, epidemiological studies associated the use of astemizole and loratadine with reduced mortality from different cancers. ${ }^{16}$

The effect of gefitinib is well known in the A549 and NCI-H1975 lung cancer cells studied, ${ }^{40,41}$ whereas the effect of astemizole has been previously reported in A549 cells. ${ }^{16}$

Because astemizole has several targets involved in cancer, ${ }^{19-28,36,37,39}$ the possible mechanisms explaining the anti-proliferative effects here observed include blockage of oncogenic Eag1 potassium channels, decrease of Eag1 mRNA expression, inhibition of $\mathrm{ABC}$ multidrug transporters (which generate resistance to gefitinib) ${ }^{14}$ and antagonism of the histamine receptor H1. On the other hand, gefitinib may decrease cell proliferation by at least two possible mechanisms. A potential mechanism is the well-known EGFR-dependent pathway inhibition. ${ }^{6} 10$ The other is EGFR-independent by blocking H2-histamine and H4-histamine receptors, since gefitinib is able to antagonize these receptors and induce cytostasis and differentiation in leukemia cells. ${ }^{43}$

Here, we also observed that the combination astemizolegefitinib at low concentrations had superior effects on the metabolic activity, survival and apoptosis of human lung cancer cells. The combination of the drugs at their $\mathrm{IC}_{20}$ decreased cell proliferation in up to $80 \%$, whereas the combination of astemizole- $\mathrm{IC}_{20}$ and gefitinib- $\mathrm{IC}_{50}$ almost completely abolished proliferation in A549 cells. The drug combination also inhibited completely the survival of both cell lines. On the other hand, increased apoptosis was exclusively observed in NCIH1975 cells only in the presence of the drug combination but not with the drugs alone. Some of the plausible mechanisms explaining the enhanced effects of the drug combination are the convergence on the histamine pathways (both can antagonize different histamine receptors), the increase in gefitinib concentration due to the blockage of $\mathrm{ABC}$ transporters by astemizole and/or the decrease in the expression of oncogenic Eag1 channels. Further studies are needed to elucidate the precise mechanism of the enhanced effects of the combination like testing the effect of other antihistamines, silencing or overexpressing the drug targets including histamine receptors, Eag1 potassium channels and $\mathrm{ABC}$ transporters, as well as testing the effect of other EGFR inhibitors.
In addition, we found that astemizole induced subcellular accumulation of Eag1 channels. More studies are needed to elucidate in which subcellular compartments this channel relocalization may be taking place and if this rearrangement may be associated with the anti-proliferative mechanism of astemizole. The cell lines displayed some differences in the drug responses. Despite that both cell lines were derived from biopsies of patients with NSCLC, the differences may reflect the heterogeneity of lung cancer cells observed in patients. However, the superior effect of the drug combination was maintained in both cell lines in several experimental approaches.

Astemizole is a nonsedating second-generation antihistamine that does not cross the blood-brain barrier. ${ }^{44}$ This molecule was withdrawn from the market in several countries especially because severe cardiac side effects including prolongation of the Q-T segment and Torsade de Pointes were observed in cases of overdose. ${ }^{20,45-47}$ Our results show very strong effects when low concentrations of astemizole and gefitinib were combined. Then, astemizole may be safely administered at proper dose, and especially in combination with gefitinib, the dose may be even lowered Despite that several studies explaining the precise mechanism of the combination effect are needed, these results suggest the combination astemizole-gefitinib as a novel therapeutic strategy for lung cancer that may help to decrease mortality from this disease.

\section{Acknowledgments}

This work was partially supported by AstraZeneca, Mexico (Project 07-1057 to JC). A similar abstract of this paper was presented at the 12th World Cancer Conference 2016 as a conference talk with interim findings. The abstract was published in "Scientific Tracks Abstracts" in Journal of Cancer Science \& Therapy: https://www.omicsonline.org/proceedings/thecombination-astemizolegefitinib-as-a-novel-and-promisingtherapy-for-human-lung-cancer-in-vitro-studies-54573.html. DOI:10.4172/1948-5956.C1.084.

\section{Disclosure}

CAC-A and MV-Y received financial support for undergraduate studies from Universidad de las Fuerzas Armadas, ESPE, Ecuador. The authors report no other conflicts of interest in this work.

\section{References}

1. Ferlay J, Soerjomataram I, Ervik M, et al. Cancer Incidence and Mortality Worldwide: IARC CancerBase No 11. Lyon, France: International Agency for Research on Cancer; 2013. GLOBOCAN 2012 v1. 
2. Torre LA, Bray F, Siegel RL, Ferlay J, Lortet-Tieulent J, Jemal A. Global cancer statistics, 2012. CA Cancer J Clin. 2015;65(2):87-108.

3. Esposito L, Conti D, Ailavajhala R, Khalil N, Giordano A. Lung cancer: are we up to the challenge? Curr Genomics. 2010;11(7):513-518.

4. de Groot P, Munden RF. Lung cancer epidemiology, risk factors, and prevention. Radiol Clin North Am. 2012;50(5):863-876.

5. Chan BA, Hughes BG. Targeted therapy for non-small cell lung cancer: current standards and the promise of the future. Trans Lung Cancer Res. 2015;4(1):36.

6. Liu X, Wang P, Zhang C, Ma Z. Epidermal growth factor receptor (EGFR): a rising star in the era of precision medicine of lung cancer. Oncotarget. 2017;8(30):50209-50220.

7. Zhu Q, Zhang S, Ding X, He B, Zhang H. Driver genes in non-small cell lung cancer: characteristics, detection methods, and targeted therapies. Oncotarget. 2017;8(34):57680-57692.

8. Jackman DM, Yeap BY, Sequist LV, et al. Exon 19 deletion mutations of epidermal growth factor receptor are associated with prolonged survival in non-small cell lung cancer patients treated with gefitinib or erlotinib. Clin Cancer Res. 2006;12(13):3908-3914.

9. Rosell R, Moran T, Queralt C, et al. Screening for epidermal growth factor receptor mutations in lung cancer. $N$ Engl J Med. 2009;361(10): 958-967.

10. Zhang $\mathrm{H}$. Three generations of epidermal growth factor receptor tyrosine kinase inhibitors developed to revolutionize the therapy of lung cancer. Drug Des Devel Ther. 2016;10:3867.

11. Kris MG, Natale RB, Herbst RS, et al. Efficacy of gefitinib, an inhibitor of the epidermal growth factor receptor tyrosine kinase, in symptomatic patients with non-small cell lung cancer: a randomized trial. JAMA. 2003;290(16):2149-2158.

12. Hopper-Borge EA, Nasto RE, Ratushny V, Weiner LM, Golemis EA, Astsaturov I. Mechanisms of tumor resistance to EGFR-targeted therapies. Expert Opin Ther Targets. 2009;13(3):339-362.

13. Özvegy-Laczka C, Cserepes J, Elkind NB, Sarkadi B. Tyrosine kinase inhibitor resistance in cancer: role of ABC multidrug transporters. Drug Resist Updat. 2005;8(1):15-26.

14. Sharom FJ. ABC multidrug transporters: structure, function and role in chemoresistance. Pharmacogenomics. 2008;9(1):105-127.

15. Lee H, Kang S, Kim W. Drug repositioning for cancer therapy based on large-scale drug-induced transcriptional signatures. PLoS One. 2016; 11(3):e0150460.

16. Ellegaard A-M, Dehlendorff C, Vind AC, et al. Repurposing cationic amphiphilic antihistamines for cancer treatment. EBioMedicine. 2016; 9:130-139.

17. Ashburn TT, Thor KB. Drug repositioning: identifying and developing new uses for existing drugs. Nat Rev Drug Discov. 2004;3(8): 673-683.

18. Cheng F, Liu C, Jiang J, et al. Prediction of drug-target interactions and drug repositioning via network-based inference. PLoS Comput Biol. 2012;8(5):e1002503.

19. Parsons ME, Ganellin CR. Histamine and its receptors. Br J Pharmacol. 2006;147(S1):S127-S135.

20. García-Quiroz J, Camacho J. Astemizole: an old anti-histamine as a new promising anti-cancer drug. Anticancer Agents Med Chem. 2011; 11(3):307-314.

21. Reynolds J, Akhter J, Morris D. In vitro effect of histamine and histamine $\mathrm{H} 1$ and $\mathrm{H} 2$ receptor antagonists on cellular proliferation of human malignant melanoma cell lines. Melanoma Res. 1996;6(2):95-100.

22. García-Ferreiro RE, Kerschensteiner D, Major F, Monje F, Stühmer W, Pardo LA. Mechanism of block of hEag1 K+ channels by imipramine and astemizole. J Gen Physiol. 2004;124(4):301-317.

23. Diaz L, Ceja-Ochoa I, Restrepo-Angulo I, et al. Estrogens and human papilloma virus oncogenes regulate human ether-a-go-go-1 potassium channel expression. Cancer Res. 2009;69(8):3300-3307.

24. Downie BR, Sánchez A, Knötgen H, et al. Eag1 expression interferes with hypoxia homeostasis and induces angiogenesis in tumors. $J$ Biol Chem. 2008;283(52):36234-36240.

25. Pardo LA, Stühmer W. Eag1: an emerging oncological target. Cancer Res. 2008;68(6):1611-1613.
26. Wulff H, Castle NA, Pardo LA. Voltage-gated potassium channels as therapeutic targets. Nat Rev Drug Discov. 2009;8(12):982-1001.

27. Avila E, Garcia-Becerra R, Rodríguez-Rasgado JA, et al. Calcitriol down-regulates human ether a go-go 1 potassium channel expression in cervical cancer cells. Anticancer Res. 2010;30(7):2667-2672.

28. de Guadalupe Chávez-López M, Pérez-Carreón JI, Zuñiga-García V, et al. Astemizole-based anticancer therapy for hepatocellular carcinoma (HCC), and Eag1 channels as potential early-stage markers of HCC. Tumor Biol. 2015;36(8):6149-6158.

29. Pardo LA, del Camino D, Sanchez A, et al. Oncogenic potential of EAG K(+) channels. EMBO J. 1999;18(20):5540-5547.

30. Rodriguez-Rasgado JA, Acuna-Macias I, Camacho J. Eag1 channels as potential cancer biomarkers. Sensors. 2012;12(5):5986-5995.

31. Occhiodoro T, Bernheim L, Liu J-H, et al. Cloning of a human ether-àgo-go potassium channel expressed in myoblasts at the onset of fusion. FEBS Lett. 1998;434(1-2):177-182.

32. Hemmerlein B, Weseloh RM, de Queiroz FM, et al. Overexpression of Eag1 potassium channels in clinical tumours. Mol Cancer. 2006; $5(1): 41$.

33. Farias LMB, Ocaña DB, Díaz L, et al. Ether a go-go potassium channels as human cervical cancer markers. Cancer Res. 2004;64(19): 6996-7001.

34. Ousingsawat J, Spitzner M, Puntheeranurak S, et al. Expression of voltage-gated potassium channels in human and mouse colonic carcinoma. Clin Cancer Res. 2007;13(3):824-831.

35. Ortiz CS, Montante-Montes D, Saqui-Salces M, et al. Eag1 potassium channels as markers of cervical dysplasia. Oncol Rep. 2011;26(6): 1377-1383.

36. García-Quiroz J, García-Becerra R, Barrera D, et al. Astemizole synergizes calcitriol antiproliferative activity by inhibiting CYP24A1 and upregulating VDR: a novel approach for breast cancer therapy. PLoS One. 2012;7(9):e45063.

37. Ishikawa M, Fujita R, Takayanagi M, Takayanagi Y, Sasaki K. Reversal of acquired resistance to doxorubicin in K562 human leukemia cells by astemizole. Biol Pharm Bull. 2000;23(1):112-115.

38. García-Becerra R, Díaz L, Camacho J, et al. Calcitriol inhibits Ether-a go-go potassium channel expression and cell proliferation in human breast cancer cells. Exp Cell Res. 2010;316(3):433-442.

39. Kong X, Chen L, Jiao L, et al. Astemizole arrests the proliferation of cancer cells by disrupting the EZH2-EED interaction of polycomb repressive complex 2. J Med Chem. 2014;57(22):9512-9521.

40. Xu R, Shen H, Guo R, Sun J, Gao W, Shu Y. Combine therapy of gefitinib and fulvestrant enhances antitumor effects on NSCLC cell lines with acquired resistance to gefitinib. Biomed Pharmacother. 2012; 66(5):384-389.

41. Stabile LP, Lyker JS, Gubish CT, Zhang W, Grandis JR, Siegfried JM. Combined targeting of the estrogen receptor and the epidermal growth factor receptor in non-small cell lung cancer shows enhanced antiproliferative effects. Cancer Res. 2005;65(4):1459-1470.

42. de Guadalupe Chávez-López M, Hernández-Gallegos E, VázquezSánchez AY, Gariglio P, Camacho J. Antiproliferative and proapoptotic effects of astemizole on cervical cancer cells. Int J Gynecol Cancer. 2014;24(5):824-828.

43. Yadav M, Singh AK, Kumar H, et al. Epidermal growth factor receptor inhibitor cancer drug gefitinib modulates cell growth and differentiation of acute myeloid leukemia cells via histamine receptors. Biochim Biophys Acta. 2016;1860(10):2178-2190.

44. Nolen TM. Sedative effects of antihistamines: safety, performance, learning, and quality of life. Clin Ther. 1997;19:39-55.

45. Kingswood JC, Routledge PA, Lazaris JH. A report of overdose with astemizole. Hum Toxicol. 1986;5:43-44.

46. Bishop RO, Gaudry PL. Prolongated Q-T interval following astemizole overdose. Arch Emerg Med. 1989;6:63-65.

47. Craft TM. Torsade de pointes after astemizole overdose. $\mathrm{Br}$ Med $\mathrm{J}$. 1986;292:660. 
OncoTargets and Therapy

\section{Publish your work in this journal}

OncoTargets and Therapy is an international, peer-reviewed, open access journal focusing on the pathological basis of all cancers, potential targets for therapy and treatment protocols employed to improve the management of cancer patients. The journal also focuses on the impact of management programs and new therapeutic agents and protocols on The manuscript management system is completely online and includes a very quick and fair peer-review system, which is all easy to use. Visit http://www.dovepress.com/testimonials.php to read real quotes from published authors.

Submit your manuscript here: http://www.dovepress.com/oncotargets-and-therapy-journal 